\title{
Longitudinal study of self-awakening and sleep/wake habits in adolescents
}

\author{
This article was published in the following Dove Press journal: \\ Nature and Science of Sleep \\ 3I August 2012 \\ Number of times this article has been viewed
}

\author{
Hiroki Ikeda' \\ Mitsuo Hayashi ${ }^{2}$ \\ 'Department of Adult Mental Health, \\ National Institute of Mental Health, \\ National Center of Neurology and \\ Psychiatry, Tokyo; ${ }^{2}$ Department of \\ Behavioral Sciences, Graduate School \\ of Integrated Arts and Sciences, \\ Hiroshima University, Hiroshima, \\ Japan
}

\begin{abstract}
Self-awakening is the ability to awaken without external assistance at a predetermined time. Cross-sectional studies reported that people who self-awaken have sleep/wake habits different from those of people who use external means to wake from sleep. However, no longitudinal study has examined self-awakening. The present study investigated self-awakening, both habitual and inconsistent, compared to awakening by external means in relation to sleep/wake schedules for five consecutive years in 362 students (starting at mean age $15.1 \pm 0.3$ years). Students who self-awakened consistently for five consecutive years $(5 \%$ of all students) went to bed earlier than those who inconsistently self-awakened (mixed group, $40 \%$ ) or consistently used forced awakening by external means ( $56 \%)$. Awakening during sleep was more frequent and sleep was lighter in the consistently self-awakened group than in the mixed and consistently forced-awakened groups. However, daytime dozing was less frequent and comfort immediately after awakening was greater for the consistently self-awakened group than for the mixed and consistently forced-awakened groups. These results indicate that the three groups have different sleep/wake habits. Previous studies of self-awakening using crosssectional survey data may have confounded both consistent and inconsistent self-awakening habits. A longitudinal study is necessary to clarify the relationship between the self-awakening habit and sleep/wake patterns.
\end{abstract}

Keywords: habitual self-awakening, sleep/wake pattern, adolescent

\section{Introduction}

Awakening from sleep is a normal biological response in human beings. There are two kinds of awakening: forced awakening and spontaneous awakening. Forced awakening uses external means such as an alarm. Spontaneous awakening is awakening without external means; it may be divided into natural awakening and self-awakening. Natural awakening is awakening from sleep without an external stimulus at unexpected times, such as during normal nighttime sleep. Self-awakening is awakening at a predetermined time. The present study focuses on self-awakening.

Both the accuracy and success rate of self-awakening have been experimentally examined..$^{1-5}$ More than half of the people who have the ability to self-awaken successfully awakened within 30 minutes of the predetermined time. For example, seven participants succeeded on nine of 14 days (64\%) in a sleep laboratory, ${ }^{2}$ and 15 participants succeeded on 35 of 44 nights $(80 \%)$ at their homes. ${ }^{3}$ Survey studies indicate that many people habitually self-awaken in daily life; for example, $52 \%$ of 269 adults (aged $21-84$ years) ${ }^{3}$ and $10.3 \%$ of 643 university students ${ }^{6}$ reported habitually self-awakening. People who have a habit of self-awakening in the morning have
Correspondence: Hiroki lkeda Department of Adult Mental Health, National Institute of Mental Health, National Center of Neurology and Psychiatry, 4-I-I Ogawa-Higashi, Kodaira, Tokyo 187-8502, Japan

Tel $+8|4234| 27||$

Fax +8I 42346 I944

Email hikeda@ncnp.go.jp 
regular sleep/wake schedules, tended to have a morningness chronotypology, awakened comfortably in the morning, and had less daytime dozing. ${ }^{3,6}$

However, sleep/wake habits often change, especially in young adults. Therefore, it is necessary to examine whether the habit of self-awakening is a stable habit. The present study investigated the characteristics of sleep/wake habits, subjective sleep qualities, and daytime symptoms in adolescents who had a consistent habit of self-awakening for five consecutive years compared with adolescents who inconsistently self-awakened and others who used forced awakening.

\section{Methods}

\section{Participants}

Japanese students $(\mathrm{N}=379)$ enrolled at the National College of Technology from 2002-2004 answered a questionnaire for 5 consecutive years each May from 2002-2008. All the students participated voluntarily in this study, and they had the same education level. The data from 362 students (68 females, 294 males) who answered the questionnaire accurately for 5 consecutive years were analyzed. Their mean age at the time of the first investigation was $15.1 \pm 0.3$ years.

\section{Questionnaires}

\section{Habit of self-awakening}

Developed on the basis of the work of Moorcroft et $\mathrm{al}^{3}$ and Matsuura et al, ${ }^{6}$ the following question was used to examine the habit of self-awakening: "How do you usually awaken in the morning?" Participants who chose the following answers were categorized as habitual self-awakening: "I awaken by myself without using an alarm" or "I use an alarm yet awaken before the alarm goes off." Those who chose the following were categorized as not having the habit of self-awakening: "I use an alarm but sometimes awaken before the alarm goes off" or "I use an alarm and do not awaken before the alarm goes off."

\section{Sleep/wake habit, subjective sleep quality, and daytime symptoms}

This study used a questionnaire about sleep/wake habits that was developed in a previous survey. ${ }^{7}$ The questionnaire consisted of 24 items about sleep/wake habits (six items), subjective quality of sleep (five items), daytime symptoms (three items), and others. Items on sleep/wake habits concerned habitual bedtime, wake-up time, and sleep times on weekdays and on weekends. Subjective sleep quality consisted of sleep latency (minutes), number of awakenings after sleep onset, sleep depth (one: deep; five: light), time from awakening to getting out of bed (minutes), and subjective comfort after awakening (one: bad; five: good). The daytime symptoms included number of naps, dozing off, and sleepiness per week.

This questionnaire had been previously conducted with about 5500 Japanese people ranging from infants to individuals of advanced age, and its construct validity was confirmed. ${ }^{7}$ However, its reliability was not fully confirmed. In the present study, reliability was evaluated by the test-retest method by calculating the Pearson's product moment correlations between years, such as first and second, second and third, third and fourth, and fourth and fifth years.

\section{Morningness-eveningness (ME) type}

A Japanese version ${ }^{8}$ of the ME scale was used to evaluate circadian preference. ${ }^{9}$ The Japanese version of the ME scale has been confirmed to have high reliability ${ }^{8}$ and validity. ${ }^{10}$ The scale consists of 19 items, and the ME scores are divided into the following five categories: definitely evening type (16-30 points), moderately evening type (31-41 points), intermediate type (42-58 points), moderately morning type (59-69 points), and definitely morning type (70-86 points).

All questionnaire items were used from 2002-2008 except for ME items, which were used from 2002-2007.

\section{Statistical analysis}

Students were categorized into the following three groups: the consistently self-awakened group (CSA) comprised those who consistently reported self-awakening for 5 consecutive years. The mixed group (MIX) comprised those who reported self-awakening in some years but did not in other years. The consistently forced-awakened group (CFA) comprised those who consistently reported being awakened by an alarm or other external means for five consecutive years.

A two-way mixed model analysis of variance was performed with group (CSA, MIX, or CFA) and time (first to fifth year) as factors. The degrees of freedom were adjusted by the Huynh-Feldt epsilon. Post hoc comparisons were performed using the Bonferroni procedure.

\section{Results}

The number of students (total $\mathrm{N}=362$ ) who had a habit of self-awakening in the first to fifth years was $94(26 \%)$, $67(19 \%), 62(17 \%), 62(17 \%)$, and $58(16 \%)$, respectively. Overall, only 17 students (5\%; twelve males and five females) were classified as CSA. Two hundred and one students (56\%; 154 males and 47 females) were classified as CFA. 
The number of students in the MIX group (144 students; 128 males and 16 females; 40\%) that self-awakened in the first, second, third, and fourth year was 78 (54\%), 32 (22\%), $20(14 \%)$, and $14(10 \%)$, respectively.

The 1-year test-retest correlation coefficients of the questionnaire items on sleep/wake habit, subjective sleep quality, and daytime symptoms ranged from $0.18-0.81$ (all $P<0.01$ ). These correlation coefficients were transformed into $z^{\prime}$-scores and averaged between first and second, second and third, third and fourth, and fourth and fifth years. The $\mathrm{z}^{\prime}$-scores were then retransformed into correlation coefficients. Accordingly, the reliability coefficients were $0.43,0.50,0.48$, and 0.46 between first and second, second and third, third and fourth, and fourth and fifth years, respectively. These values indicate an almost large effect size. ${ }^{11}$

Table 1 shows the results of the analysis of variance. There were no significant interactions of group by year. Regarding sleep/wake habits (Figure 1 and Table 2), there were significant main effects of group for bedtime $(P<0.01)$, wake-up time $(P<0.01)$, and sleep time $(P<0.001)$ on weekdays. The CSA group went to bed earlier than both the MIX and CFA groups $(P<0.05)$, got up earlier than the MIX group $(P<0.05)$, and slept longer than the CFA group $(P<0.05)$. The MIX group woke up later $(P<0.01)$ and slept longer $(P<0.05)$ than the CFA group. For weekends, the main effect of group for bedtime was also significant $(P<0.05)$.
The CSA group went to bed earlier than the MIX and CFA groups $(P<0.05)$.

There were significant main effects of group for the morningness chronotypology score $(P<0.01)$. Post hoc comparisons revealed that the MIX group was higher in morningness than the CFA group $(P<0.01)$. There was no significant difference between the CSA group and the MIX or CFA groups. In Figure 1, however, it appears that the ME score of the CSA group changed from the first year to the second year. Therefore, a 3 (group: CSA, MIX, or CFA) $\times 4$ (year: 2-5) analysis of variance was performed. The results showed a significant main effect of group $(F[2117]=6.610$; $P<0.01)$. The mean ME scores of the CSA and MIX groups from the second to fifth years were significantly higher than the ME scores of the CFA group $(P<0.05)$.

Regarding subjective sleep quality and daytime symptoms, there were significant main effects of group for sleep depth $(P<0.05)$, number of awakenings after sleep onset $(P<0.001)$, comfort immediately after awakening $(P<0.05)$, and daytime dozing $(P<0.05$; Table 1$)$. Although the CSA group awakened during sleep more frequently than the MIX $(P<0.05)$ and CFA groups $(P<0.001$; Figure 2 and Table 2) and rated their sleep to be lighter than the CFA group $(P<0.10)$, they were more comfortable at awakening than the CFA group $(P<0.05)$. Although the CFA group awakened less frequently than the MIX group during sleep

Table I Main effects and interactions of group and year for sleep/wake habit, subjective sleep estimation, and daytime symptoms

\begin{tabular}{|c|c|c|c|c|c|c|c|c|c|c|}
\hline & \multicolumn{3}{|c|}{ Group } & \multicolumn{4}{|c|}{ Year } & \multicolumn{3}{|c|}{ Interaction } \\
\hline & $\mathbf{F}$ & df & $P$ & $\mathbf{F}$ & df & $\varepsilon$ & $\boldsymbol{P}$ & $\mathbf{F}$ & df & $P$ \\
\hline \multicolumn{11}{|l|}{ Bedtime } \\
\hline Week day & 7.15 & 2,359 & $<0.01$ & 7.44 & 4,1436 & 0.870 & $<0.001$ & 0.54 & 8,1436 & NS \\
\hline Week end & 3.94 & 2,358 & $<0.05$ & 3.55 & 4,1432 & 0.876 & $<0.05$ & 1.46 & 8,1432 & NS \\
\hline \multicolumn{11}{|l|}{ Wake-up time } \\
\hline Week day & 7.23 & 2,357 & $<0.0$ I & 5.63 & 4,1428 & 0.832 & $<0.001$ & 0.62 & 8,1428 & NS \\
\hline Week end & 2.31 & 2,356 & NS & 1.23 & 4, 1424 & 0.917 & NS & 1.20 & 8,1424 & NS \\
\hline \multicolumn{11}{|l|}{ Sleep time } \\
\hline Week day & 8.06 & 2,353 & $<0.001$ & 9.77 & 4,1412 & 0.923 & $<0.001$ & 0.86 & 8,1412 & NS \\
\hline Week end & 0.73 & 2,352 & NS & 1.85 & 4, 1408 & 0.922 & NS & 0.39 & 8,1408 & NS \\
\hline Morningness score & 5.69 & 2,106 & $<0.01$ & 3.00 & 4,424 & 0.937 & $<0.05$ & 1.66 & 8,424 & NS \\
\hline \multicolumn{11}{|l|}{ Subjective sleep estimation } \\
\hline Sleep latency & 0.80 & 2,349 & NS & 0.91 & 4,1396 & 0.863 & NS & 1.67 & 8,1396 & NS \\
\hline Sleep depth & 3.30 & 2,349 & $<0.05$ & 0.97 & 4,1396 & 0.968 & NS & 0.98 & 8,1396 & NS \\
\hline Number of awakenings & 9.24 & 2,353 & $<0.001$ & 0.84 & 4,1412 & 0.941 & NS & 0.23 & 8,1412 & NS \\
\hline Bed out latency & 1.33 & 2,349 & NS & 1.64 & 4,1396 & 0.878 & NS & 0.69 & 8,1396 & NS \\
\hline Comfort after awakening & 3.37 & 2,357 & $<0.05$ & 1.78 & 4,1428 & 0.986 & NS & 0.89 & 8,1428 & NS \\
\hline \multicolumn{11}{|l|}{ Daytime symptoms } \\
\hline Nap & 0.72 & 2,349 & NS & 0.44 & 4,1396 & 0.965 & NS & 1.72 & 8,1396 & $<0.10$ \\
\hline Doze off & 4.61 & 2,336 & $<0.05$ & 2.95 & 4,1344 & 0.968 & $<0.05$ & 0.81 & 8,1344 & NS \\
\hline Sleepiness & 2.06 & 2,335 & NS & 1.19 & 4,1340 & 0.960 & NS & 0.91 & 8,1340 & NS \\
\hline
\end{tabular}

Abbreviations: $\mathrm{df}$, degrees of freedom; NS, not significant. 

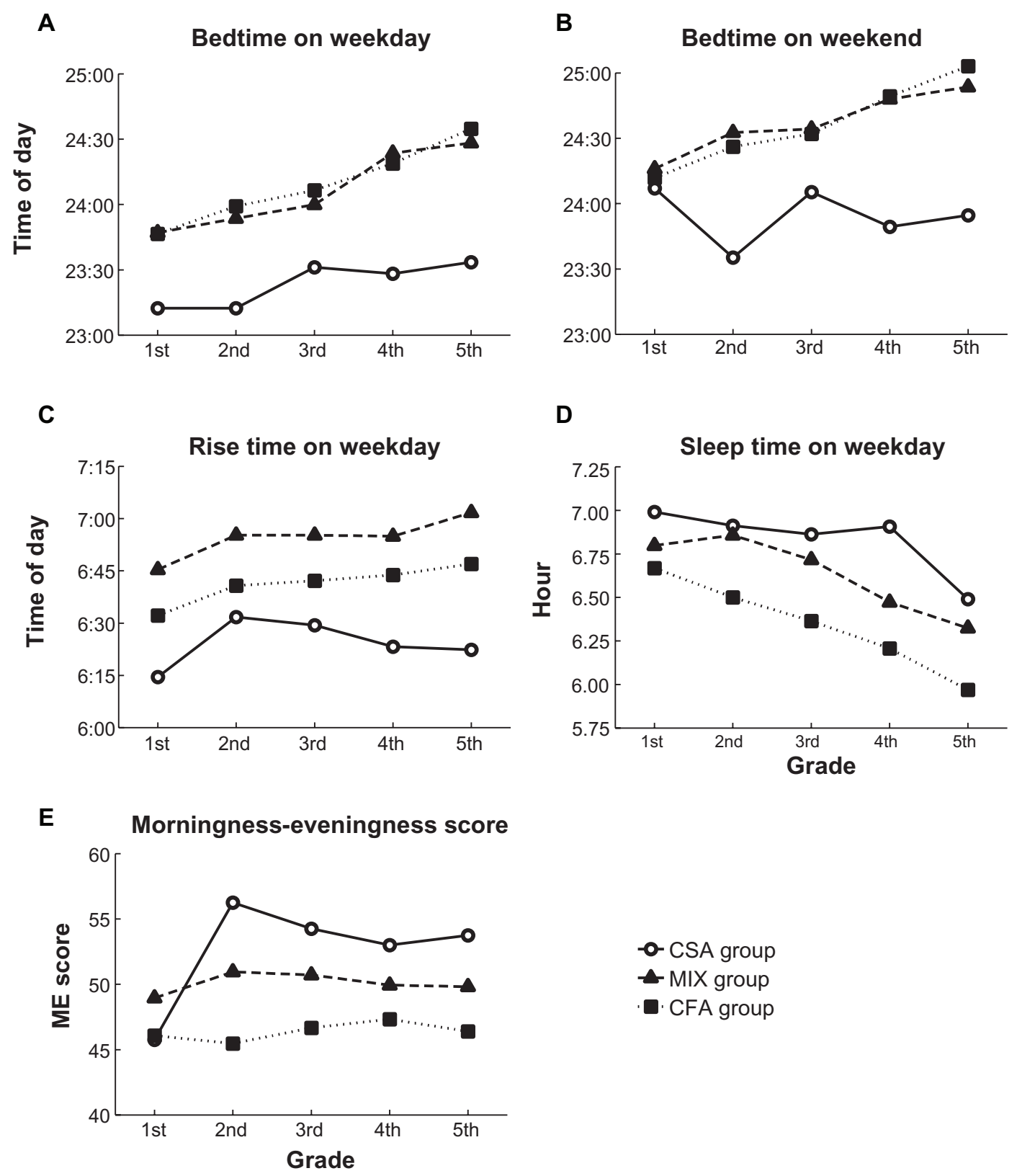

- MIX group

- CFA group

Figure I Sleep/wake habits in each group for 5 years.

Abbreviations: CFA, consistently forced-awakened group; CSA, consistently self-awakened group; ME, morningness-eveningness; MIX, mixed group.

$(P<0.05)$, they more frequently dozed off in the daytime than the CSA and MIX groups $(P<0.10)$.

In addition, there were significant main effects of year for bedtime $(P<0.001)$, wake-up time $(P<0.001)$, sleep time on weekdays $(P<0.001)$, bedtime on weekends $(P<0.05)$, morningness score $(P<0.05)$, and daytime dozing $(P<0.05$; Table 1). Bedtimes on weekdays were later in the fourth and fifth years compared with the first and the second years $(P<0.01$; Figure 1 and Table 3$)$. Wake-up time on weekdays was earlier in the first year than the other years $(P<0.01)$. Sleep time on weekdays was longer in the first to third years than in the fifth year $(P<0.01)$. The morningness score was lower in the first year than in the second year $(P<0.05)$. Dozing off was more frequent in the fourth year than the first year $(P<0.05$; Figure 2$)$.

\section{Discussion}

The present study surveyed the characteristics of awakening, sleep/wake habits, subjective sleep quality, and daytime symptoms in adolescents.

The reliability ${ }^{8}$ and validity ${ }^{10}$ of the ME questionnaire were confirmed. Construct validity was confirmed for the 
Table 2 Parameters of the sleep/wake habit, subjective sleep estimation, and daytime symptoms in each group

\begin{tabular}{|c|c|c|c|}
\hline & CSA group & MIX group & CFA group \\
\hline \multicolumn{4}{|l|}{ Bedtime (hours) } \\
\hline Week day & $23.39(0.19)^{\mathrm{a}}$ & $24.11(0.07)^{b}$ & $24.15(0.06)^{b}$ \\
\hline Week end & $23.91(0.25)^{\mathrm{a}}$ & $24.62(0.08)^{b}$ & $24.6 \mathrm{I}(0.07)^{\mathrm{b}}$ \\
\hline \multicolumn{4}{|c|}{ Wake-up time (hours) } \\
\hline Week day & $6.40(0.16)^{\mathrm{a}}$ & $6.91(0.06)^{b}$ & $6.69(0.05)^{\mathrm{a}}$ \\
\hline Week end & $8.23(0.30)$ & $8.73(0.10)$ & $8.86(0.09)$ \\
\hline \multicolumn{4}{|l|}{ Sleep time (hours) } \\
\hline Week day & $6.83(0.18)^{\mathrm{a}}$ & $6.63(0.06)^{a}$ & $6.34(0.05)^{\mathrm{b}}$ \\
\hline Week end & $8.12(0.33)$ & $7.94(0.11)$ & $8.10(0.09)$ \\
\hline Morningness score & $52.60(3.09)$ & $50.08(0.87)^{\mathrm{a}}$ & $46.39(0.83)^{\mathrm{b}}$ \\
\hline \multicolumn{4}{|c|}{ Subjective sleep estimation } \\
\hline $\begin{array}{l}\text { Sleep latency } \\
\text { (minutes) }\end{array}$ & $19.32(3.37)$ & $17.06(1.10)$ & I $5.75(0.93)$ \\
\hline Sleep depth ${ }^{\dagger 1}$ & $2.44(0.19)$ & $2.14(0.07)$ & $1.99(0.06)$ \\
\hline $\begin{array}{l}\text { Number of } \\
\text { awakenings }\end{array}$ & $0.66(0.12)^{\mathrm{a}}$ & $0.32(0.04)^{b}$ & $0.18(0.03)^{c}$ \\
\hline $\begin{array}{l}\text { Bed out latency } \\
\text { (minutes) }\end{array}$ & $3.91(1.26)$ & $6.07(0.43)$ & $5.75(0.36)$ \\
\hline $\begin{array}{l}\text { Comfort after } \\
\text { awakening }^{\dagger 2}\end{array}$ & $3.58(0.22)^{\mathrm{a}}$ & $3.08(0.08)$ & $2.99(0.06)^{b}$ \\
\hline \multicolumn{4}{|c|}{ Number of daytime symptoms ${ }^{\dagger 3}$} \\
\hline Nap & $0.77(0.19)$ & $0.60(0.07)$ & $0.69(0.06)$ \\
\hline Doze off & I.88 $(0.37)^{\mathrm{a}}$ & $2.36(0.13)^{\mathrm{a}}$ & $2.77(0.1 \mathrm{I})^{\mathrm{b}}$ \\
\hline Sleepiness & $3.65(0.42)$ & $3.86(0.15)$ & $4.20(0.12)$ \\
\hline
\end{tabular}

Notes: Values in parentheses represent standard deviation; there is a significant difference $(P<0.05)$ between "a," "b," and "c;" "'response scale: I deep, 5 light; ${ }^{+2}$ response scale: I very bad, 5 very good; ${ }^{+3}$ number per week.

Abbreviations: CFA, consistently forced-awakened group; CSA, consistently selfawakened group; MIX, mixed group.

questionnaire items on sleep/wake habits, subjective sleep quality, and daytime symptoms. ${ }^{7}$ To assess the reliability of the items, a 1-year test-retest method was utilized. Resulting reliability coefficients ranged from $0.43-0.50$. These values reflect a moderate correlation and have an almost large effect size,$^{11}$ suggesting that this questionnaire has satisfactory reliability.

For any given year, $16 \%-26 \%$ (mean $19 \%$ ) of the students reported that they habitually self-awakened that year. However, only one-quarter of these students ( $5 \%$ of all 362 students) consistently self-awakened for 5 consecutive years. In comparison, $10.3 \%$ of university students in a cross-sectional study who were several years older than the participants in the present study reported self-awakening. ${ }^{6}$ Students with consistent habits of self-awakening at a predetermined time went to sleep earlier, got up earlier in the morning, slept for a longer time, and had higher ME scores than did students who did not habitually self-awaken. These results are consistent with previous surveys on self-awakening among university students ${ }^{6}$ and adults. ${ }^{3}$ These cross-sectional studies reported that people who self-awaken got up and went to bed earlier, had higher ME scores, and were more consistent in their nocturnal sleep time than those who did not habitually self-awaken. ${ }^{3,6}$ These results lead to the conclusion that individuals who consistently self-awake have a morningness chronotypology and regular sleep/wake schedules.

Studies that examined the effects of self-awakening at an unusual time found that it disturbed sleep, ${ }^{12}$ for example, by extending sleep latency ${ }^{2}$ and increasing the number of awakenings. ${ }^{1}$ However, Matsuura et $\mathrm{al}^{6}$ found that self-awakening at a usual time did not harm sleep, but was associated with improved mood at awakening and less dozing off in the daytime. The results of the present study are consistent with Matsuura et al's findings. Students who had the habit of self-awakening for 5 consecutive years felt better after awakening and dozed off less in the daytime compared with students who did not habitually self-awaken. Other studies have reported that self-awakening can prevent sleep inertia. ${ }^{13,14}$ Sleep inertia is the state of lowered arousal that occurs immediately after awakening ${ }^{15,16}$ from normal nocturnal sleep. ${ }^{17}$ Furthermore, it was previously found that self-awakening could reduce daytime sleepiness. ${ }^{18}$ Therefore, except for the case of self-awakening at an unusual time, it is likely that self-awakening has positive effects on daily life, particularly with respect to alertness during the daytime.

Previous studies of the sleep/wake habits of self-awakening individuals were cross-sectional surveys using reports of only one time period. These studies reported that $52 \%$ of adults $^{3}$ and $10.3 \%$ of university students ${ }^{6}$ had habitual selfawakening habits. However, the habit of self-awakening is not always stable, so habitual self-awakening may occur less than the percentages reported in those studies. In the present study, $40 \%$ of all the students were mixed in their history of self-awakening; that is, they reported self-awakening in some years but not in others. Only 5\% of the students consistently self-awakened over 5 years. These students went to bed and got up earlier than the mixed type with inconsistent habits of self-awakening. To clarify the characteristics of the sleep/wake habits of the consistent type for other age groups, a longitudinal study is required.

Bedtime and awakening time on weekdays were later, and sleep time for weekday evenings lengthened with the advancing years. These findings are consistent with those of other studies that found that bedtimes gradually became later during adolescence. ${ }^{19}$ The data in the present study were gathered from 362 students who attended the same school for 5 consecutive years. Therefore, these changes may be due to developmental factors such as brain maturational changes ${ }^{20}$ 
A

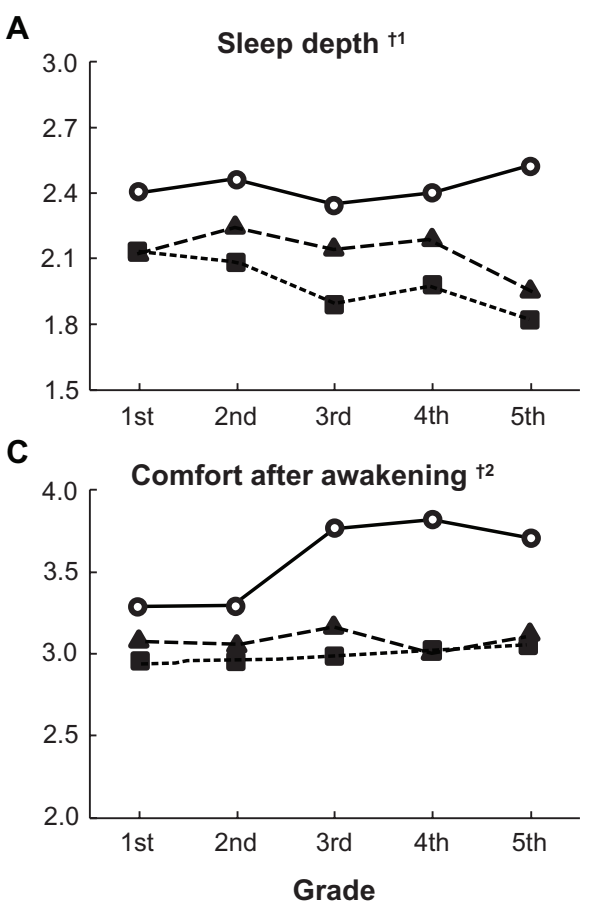

B

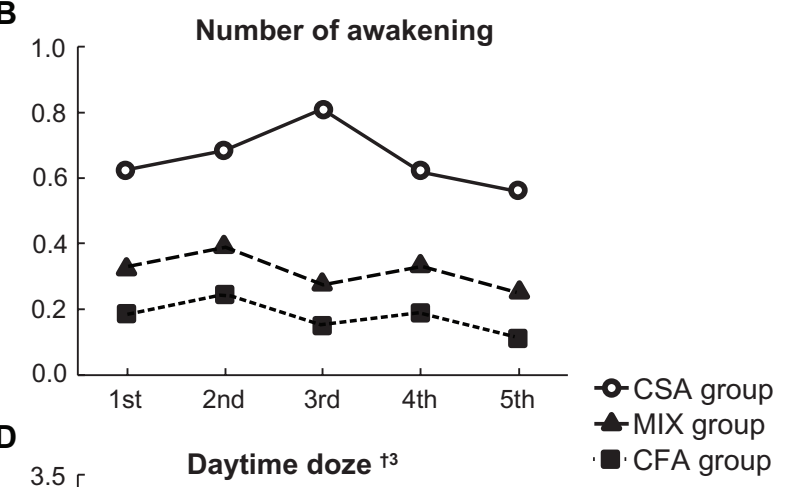

Figure 2 Subjective sleep quality and subjective ratings after awakening for 5 years.

Notes: ${ }^{+1}$ response scale: I deep, 5 light; ${ }^{+2}$ response scale: I very bad, 5 very good; ${ }^{\dagger 3}$ number per week.

Abbreviations: CFA, consistently forced-awakened group; CSA, consistently self-awakened group; MIX, mixed group.

and/or social factors such as school schedules, but they are not likely to be explained by individual differences.

This study has several limitations. First, the small percentage $(\mathrm{n}=17,5 \%)$ of students who consistently self-awakened lowered the statistical power of the analysis. Further research with larger samples is needed. Second, because of the small number of female participants, gender differences could not be investigated. However, gender differences in sleep/wake habits among adolescents have been reported. ${ }^{21}$ Further work is required to clarify gender differences in the habit

Table 3 Parameters of the sleep/wake habit, subjective sleep estimation, and daytime symptoms for 5 years

\begin{tabular}{|c|c|c|c|c|c|}
\hline & First year & Second year & Third year & Fourth year & Fifth year \\
\hline \multicolumn{6}{|l|}{ Bedtime (hours) } \\
\hline Week day & $23.59(0.12)^{\mathrm{a}}$ & $23.70(0.09)^{\mathrm{a}}$ & $23.88(0.13)$ & $24.06(0.10)^{\mathrm{b}}$ & $24.20(0.10)^{\mathrm{b}}$ \\
\hline Week end & $24.19(0.11)$ & $24.19(0.12)^{a}$ & $24.40(0.14)$ & $24.48(0.12)$ & $24.62(0.14)^{b}$ \\
\hline \multicolumn{6}{|l|}{ Wake-up time (hours) } \\
\hline Week day & $6.5 \mathrm{I}(0.06)^{\mathrm{a}}$ & $6.7 \mathrm{I}(0.07)^{\mathrm{b}}$ & $6.7 \mathrm{I}(0.07)^{\mathrm{b}}$ & $6.68(0.07)^{b}$ & $6.73(0.08)^{\mathrm{b}}$ \\
\hline Week end & $8.53(0.16)$ & $8.83(0.15)$ & $8.48(0.20)$ & $8.49(0.16)$ & $8.71(0.16)$ \\
\hline \multicolumn{6}{|l|}{ Sleep time (hours) } \\
\hline Week day & $6.82(0.08)^{a}$ & $6.76(0.08)^{\mathrm{a}}$ & $6.65(0.09)^{\mathrm{a}}$ & $6.65(0.10)$ & $6.26(0.1 \mathrm{I})^{\mathrm{b}}$ \\
\hline Week end & $8.20(0.20)$ & $8.34(0.20)$ & $7.90(0.18)$ & $7.97(0.17)$ & $7.85(0.17)$ \\
\hline Morningness score & $46.93(1.30)^{\mathrm{a}}$ & $50.89(1.47)^{\mathrm{b}}$ & $50.55(I .4 I)$ & $50.09(1.38)$ & $49.99(1.32)$ \\
\hline \multicolumn{6}{|l|}{ Subjective sleep estimation } \\
\hline Sleep latency (minutes) & $16.76(1.35)$ & $16.17(1.69)$ & I8.40 (I.57) & $17.02(1.37)$ & I8.52 (I.79) \\
\hline Sleep depth ${ }^{\dagger 1}$ & $2.23(0.10)$ & $2.27(0.10)$ & $2.13(0.09)$ & $2.20(0.10)$ & $2.10(0.09)$ \\
\hline Number of awakenings & $0.38(0.06)$ & $0.44(0.08)$ & $0.42(0.07)$ & $0.38(0.06)$ & $0.31(0.06)$ \\
\hline Bed out latency (minutes) & $5.08(0.69)$ & $4.77(0.59)$ & $4.44(0.53)$ & $5.75(0.68)$ & $6.19(0.86)$ \\
\hline Comfort after awakening ${ }^{\dagger 2}$ & $2.90(0.11)$ & $2.90(0.11)$ & $2.69(0.11)$ & $2.72(0.10)$ & $2.7 I(0.1 I)$ \\
\hline \multicolumn{6}{|l|}{ Number of daytime symptoms ${ }^{\dagger 3}$} \\
\hline Nap & $0.59(0.10)$ & $0.75(0.09)$ & $0.64(0.12)$ & $0.72(0.12)$ & $0.72(0.13)$ \\
\hline Doze off & $2.00(0.20)^{\mathrm{a}}$ & $2.43(0.20)$ & $2.43(0.20)$ & $2.69(0.19)^{b}$ & $2.13(0.19)$ \\
\hline Sleepiness & $3.98(0.22)$ & $4.13(0.23)$ & $3.98(0.23)$ & $3.85(0.22)$ & $3.59(0.23)$ \\
\hline
\end{tabular}

Notes: Values in parentheses represent standard deviation; there is a significant difference $(P<0.05)$ between "a" and "b;" " ${ }^{\dagger}$ response scale: I deep, 5 light; ${ }^{\dagger 2}$ response scale: I very bad, 5 very good; ${ }^{\dagger 3}$ number per week. 
of self-awakening. Third, the data of this study were based on self-reports, which could lead to bias. However, as seen above, the data is partially similar to a cross-sectional survey of self-awakening and sleep/wake habits. ${ }^{6}$ In addition, the results of previous studies that experimentally compared self-awakening to forced-awakening were also similar to the results of the present survey; for example, self-awakening increases the number of awakenings from sleep ${ }^{1}$ and comfortable awakening. ${ }^{13}$ This suggests that self-report bias was minimized in this study. Finally, the participants were between 15-19 years old. However, people who never use an alarm for awakening could be significantly older. ${ }^{3}$ Thus, age may influence habitual self-awakening and sleep/wake schedules. Consequently, further longitudinal research with a sample having a wider range of ages is needed.

\section{Disclosure}

The authors report no conflicts of interest in this work.

\section{References}

1. Bell CR. Awakening from sleep at a pre-set time. Percept Mot Skills. 1980;50(2):503-508.

2. Lavie P, Oksenberg A, Zomer J. "It's time, you must wake up now." Percept Mot Skills. 1979;49(2):447-450.

3. Moorcroft WH, Kayser KH, Griggs AJ. Subjective and objective confirmation of the ability to self-awaken at a self-predetermined time without using external means. Sleep. 1997;20(1):40-45.

4. Zepelin H. REM sleep and the timing of self-awakenings. Bull Psychon Soc. 1986;24(4):254-256.

5. Zung WW, Wilson WP. Time estimation during sleep. Biol Psychiatry. 1971;3(2):159-164.

6. Matsuura N, Hayashi M, Hori T. Comparison of sleep/wake habits of university students with or without a habit of self-awakening. Psychiatry Clin Neurosci. 2002;56(3):223-224.

7. Hori T, Miyashita A, Shirakawa S, Ishihara K, Fukuda K, Hayashi M. Survey on the developmental changes of sleep-wake habits and sleep problems from infants to advanced ages in Japanese population. Abstract of Research Project, Grant-in-Aid for Scientific Research (A) funded by the Japanese Ministry of Education, Science, sports and Culture, Project No. 07301013 (in Japanese), 1998.
8. Ishihara K, Miyashita A, Inugami M, Fukuda K, Yamazaki K, Miyata Y. The results of investigation by the Japanese version of MorningnessEveningness Questionnaire. Shinrigaku Kenkyu. 1986;57(2):87-91. Japanese.

9. Horne JA, Ostberg O. A self-assessment questionnaire to determine morningness-eveningness in human circadian rhythms. Int $J$ Chronobiol. 1976;4(2):97-110.

10. Ishihara K, Saitoh T, Inoue Y, Miyata Y. Validity of the Japanese version of the Morningness-Eveningness Questionnaire. Percept Mot Skills. 1984;59(3):863-866.

11. Cohen J. Statistical Power Analysis for the Behavioral Sciences. 2nd ed. Hillsdale, NJ: Lawrence Erlbaum; 1988.

12. Hawkins JS, Shaw P. Sleep satisfaction and intentional self-awakening: an alternative protocol for self-report data. Percept Mot Skills. 1990; $70(2): 447-450$.

13. Ikeda $H$, Hayashi M. The effect of self-awakening from nocturnal sleep on sleep inertia. Biol Psychol. 2010;83(1):15-19.

14. Kaida K, Nittono H, Hayashi M, Hori T. Effects of self-awakening on sleep structure of a daytime short nap and on subsequent arousal levels. Percept Mot Skills. 2003;97(3 Pt 2):1073-1084.

15. Ferrara M, De Gennaro L. The sleep inertia phenomenon during the sleep-wake transition: theoretical and operational issues. Aviat Space Environ Med. 2000;71(8):843-848.

16. Tassi P, Muzet A. Sleep inertia. Sleep Med Rev. 2000;4(4):341-353.

17. Ikeda H, Hayashi M. Effect of sleep inertia on switch cost and arousal level immediately after awakening from normal nocturnal sleep. Sleep and Biological Rhythms. 2008;6(2):120-125.

18. Ikeda H, Hayashi M. Effect of self-awakening on daytime sleepiness. Paper presented at: The Joint Congress of ASRS, JSSR, and JSC; October 24-27, 2009; Osaka, Japan.

19. Yang CK, Kim JK, Patel SR, Lee JH. Age-related changes in sleep/ wake patterns among Korean teenagers. Pediatrics. 2005;115(Suppl 1): $250-256$.

20. Campbell IG, Higgins LM, Trinidad JM, Richardson P, Feinberg I. The increase in longitudinally measured sleepiness across adolescence is related to the maturational decline in low-frequency EEG power. Sleep. 2007;30(12):1677-1687.

21. Giannotti F, Cortesi F, Sebastiani T, Ottaviano S. Circadian preference, sleep and daytime behaviour in adolescence. J Sleep Res. 2002;11(3) 191-199.
Nature and Science of Sleep

\section{Publish your work in this journal}

Nature and Science of Sleep is an international, peer-reviewed, open access journal covering all aspects of sleep science and sleep medicine, including the neurophysiology and functions of sleep, the genetics of sleep, sleep and society, biological rhythms, dreaming, sleep disorders and therapy, and strategies to optimize healthy sleep. The journal welcomes

\section{Dovepress}

original research, clinical \& epidemiological studies, reviews \& evaluations, case reports and extended reports. The manuscript management system is completely online and includes a very quick and fair peerreview system, which is all easy to use. Visit http://www.dovepress.com/ testimonials.php to read real quotes from published authors. 